\title{
ACCIÓN COMUNITARIA CON JÓVENES. DESAFÍOS GENERACIONALES
}

\author{
KLAUDIO DUARTE QUAPPER*
}

\begin{abstract}
RESUMEN
Las experiencias de acción comunitaria con jóvenes son múltiples y de larga data en nuestro país. En ellas, organizaciones de diverso tipo han intentado llevar adelante estrategias de acción en territorios y en comunidades. El presente análisis busca debatir en torno a las concepciones de comunidad y de acción comunitaria en contextos de un capitalismo salvaje; observar cómo se construyen las relaciones generacionales en estas experiencias y cuáles son las concepciones de juventudes que (re)producen; dar cuenta de las tensiones metodológicas que en ellas se van evidenciando; y plantear pistas sobre posibilidades y oportunidades que se abren al incorporan horizontes de equidad /igualdad/solidaridad generacional en esta acción comunitaria.

La hipótesis central a debatir es que la acción comunitaria con jóvenes ha carecido de perspectivas que releven los aportes juveniles como nutriente política de los procesos en desarrollo, quedándose más bien instaladas sobre nociones adultocéntricas que invisibilizan o niegan dichas contribuciones y que debilitan las posibilidades de construcción de comunidad. Esto último resulta reforzado en un contexto de individualismo que alienta el abandono de lo colectivo y lo comunitario como voluntad social.
\end{abstract}

PALABRAS CLAVE: COMUNIDAD, ACCIÓN COMUNITARIA JUVENIL, JUVENTUDES, CAPITALISMO SALVAJE

* Chileno, Sociólogo Universidad de Chile y Educador Popular; Máster en Juventud y Sociedad, Universidad de Girona; Doctorando en Sociología, Universidad Autónoma de Barcelona. Director Proyecto Anillo Juventudes (SOC 1108). Coordinador Académico del Diplomado de Postítulo en Investigación y Acción en Mundos Juveniles y del Núcleo de Investigación en Juventudes, del Departamento de Sociología de la Universidad de Chile. claudioduarte@u.uchile.cl.

El presente artículo es parte del Proyecto Anillos «Juventudes. Transformaciones socioeconómicas, sociopolíticas y socioculturales de las y los jóvenes en el Chile contemporáneo» (SOC 1108). 


\title{
AÇÃO COMUNITÁRIA COM JOVENS: DESAFIOS GERACIONAIS
}

\begin{abstract}
RESUMO
As experiências de ação comunitárias com jovens são múltiplas e de longa data em nosso país. Neles, vários tipos de organizações têm tentado realizar estratégias de ação territórios e comunidades. Esta análise tem os seguintes objetivos: discutir os conceitos de comunidade e de ação comunitária em contextos de capitalismo selvagem; observar como se constroem as relações geracionais nestas experiências e quais são as concepções de juventudes que (re)produzem; tratar das tensões metodológicas que nelas vão se evidenciando; e trazer pistas sobre possibilidades e oportunidades que se abrem ao incorporar horizontes de equidade/igualdade/solidariedade geracional nesta ação comunitária.

A hipótese central é que a ação comunitária com jovens carece de perspectivas que revelem os aportes juvenis como matrizes políticas dos processos em desenvolvimento, estando mais bem estabelecidas sobre noções adultocêntricas que invialbilizam ou negam tais contribuições e que enfraquecem as possibilidades de construção de comunidade. Isto reforça um contexto de individualismo que incentiva o abandono do coletivo e da comunidade como uma vontade social.
\end{abstract}

\section{PalaVRas CHAVE: COMUNIDADE, AÇÃo COMUNITÁRIA JUVENIL, JUVENTUDES, CAPITALISMO SELVAGEM}

\section{COMMUNITY ACTION WITH YOUNG PEOPLE. GENERATIONAL CHALLENGES}

\begin{abstract}
The experiences of youth community action are multiple and longstanding in our country. In them, various types of organizations have attempted to carry out action strategies territories and communities. The present analysis searches: to debate concerning the conceptions of community and of community action in contexts of unrestrained capitalism; to observe how the generational relations are constructed in these experiences and which are the conceptions of youths that (re) produce; realize of the methodological tensions that in them are demonstrated; and to raise tracks on possibilities and opportunities that are opened to incorporate horizons of equity/generational equality/solidarity in this community action.

The central hypothesis to discuss, is that the community action with young people have lacked perspectives that relieve the juvenile contributions as nutrient politics of the processes in development, remaining rather installed on adult- centered notions that make invisible or they deny the above mentioned contributions and that they debilitate the possibilities of construction of community. The above mentioned turns out to be reinforced in a context of individualism that encourages the abandon of the collective thing and the community thing as social will.
\end{abstract}

KEY WORDS: COMMUNITY, YOUTH COMMUNITY ACTION, YOUTHS, UNRESTRAINED CAPITALISM 


\section{INTRODUCCIÓN}

LA POLÍTICA PÚBILICA dirigida a poblaciones jóvenes en Chile, data de los últimos cuarenta y cinco años. Esta política pública se hace sistemática y comienza un despliegue, con intensidades, logros y dificultades de distinto tipo, en el contexto de un Estado de Bienestar que se intenta transformar con propuestas políticas progresistas - gobiernos demócrata cristiano y de la unidad popular (1964 a 1973) - (Del Picó, 1994), y en un contexto en que se consolida la emergencia de la diversidad de jóvenes en la sociedad chilena (Duarte, 2005). Posteriormente, las transformaciones de la estructura social chilena (Salazar y Pinto, 2002) en la dictadura militar y los gobiernos civiles siguientes, hacia una economía de raíces profundamente capitalistas, con ideología neoliberal, ha implicado un Estado que despliega la política pública hacia jóvenes con énfasis en la integración de éstos/as a los mercados laborales vía sistema educativo de amplia cobertura (Redondo, 2005); el abordaje de situaciones consideradas desviadas mediante leyes y programas públicos que hacen énfasis en la rehabilitación vía sistema penal para poblaciones jóvenes (Tijoux, 2002); la implementación de programas para estimular la participación ciudadana en los marcos que los mundos adultos consideran adecuados (Dávila y Honores, 2003); la implementación de programas específicos para fenómenos considerados alarmantes por su existencia y tasas de aumento entre la población joven del país como es el embarazo en jóvenes, el consumo de drogas y alcohol, las muertes por suicidio y causas violentas, entre otros.

En ese marco, un ámbito vinculado al despliegue de estas políticas han sido las experiencias comunitarias con poblaciones jóvenes. En ellas, organizaciones de diverso tipo - movimientos, agrupaciones, instituciones - entre otras, han intentado llevar adelante estrategias de acción en territorios y en comunidades. Estas experiencias son el objeto de nuestra observación. En dicho análisis nos interesa debatir en torno a las concepciones de comunidad y de acción comunitaria en contextos de un capitalismo salvaje; observar cómo se construyen las relaciones generacionales en las experiencias comunitarias y cuáles son las concepciones de juventudes que en ellas se (re)producen; dar cuenta de las tensiones metodológicas, en perspectiva generacional, que en ellas se van evidenciando; y plantear pistas sobre cuáles son las posibilidades-oportunidades que se abren si se incorporan horizontes de equidad/igualdad/solidaridad generacional en la acción comunitaria con jóvenes. 
La hipótesis central a debatir es que la acción comunitaria con jóvenes ha carecido de perspectivas que releven los aportes juveniles como nutriente política de los procesos en desarrollo, quedándose más bien instaladas sobre nociones adultocéntricas que invisibilizan o niegan dichas contribuciones y que debilitan las posibilidades de construcción de comunidad. Esto último resulta reforzado en un contexto de individualismo que alienta el abandono de lo colectivo y lo comunitario como voluntad social.

En términos específicos, se establecerán relaciones de las ideas señaladas en la hipótesis con la falta de concepciones sobre acción comunitaria que sin perder globalidad consideren las especificidades de los mundos juveniles; se mostrará cómo la consideración de perspectivas generacionales en el análisis de lo social, abre dimensiones hasta ahora poco exploradas para superar tanto la invisibilización de los aportes juveniles como la juvenilización del trabajo con jóvenes; se plantearán cuestionamientos en torno a nudos críticos del quehacer metodológico que la observación de la práctica permiten sistematizar; y se elaborarán pistas para contribuir a potenciar las posibilidades de equidad, igualdad y solidaridad generacional desde experiencias con jóvenes.

\section{2. (NO)COMUNIDAD EN CONTEXTO DE CAPITALISMO SALVAJE}

Uno de los debates que necesitamos abordar para reflexionar en torno a la acción comunitaria refiere a la idea de comunidad. Más allá de las enunciaciones sobre la polisemia del concepto y sobre lo que algunos autores denominan «confusiones» en su uso (Úcar y Llena, 2009), precisamos de una cierta conceptualización que aporte claridad respecto a qué nos referimos con las nociones de comunidad y lo comunitario. Siendo necesario este debate es preciso desplegarlo haciendo referencia directa del contexto en que se dan estos procesos y esta reflexión; ello incide directamente en las características de lo observado y de los códigos con que dicha mirada se despliega.

Diversos autores europeos, caracterizan la situación social en la época actual, principalmente desde cuatro procesos que estarían desplegándose de manera simultánea: la globalización, los procesos de individualización, el despliegue de las tecnologías de la información, y los modos de hacer política desde los gobiernos y desde la sociedad civil (Úcar y Llena, 2009; Beck, 1999; Bauman, 2002). Todos ellos estarían produciendo situaciones de fragmentación, retraimiento y desarticulación de lo comunitario, que justificarían los actuales proce- 
sos de acción comunitaria como una «vuelta a lo comunitario» (Úcar y Llena, 2009).

Cada uno de dichos procesos, está también en desarrollo e incidiendo en América Latina y El Caribe, y en específico en Chile. Por ello la lectura a realizar intenta hacer puentes reflexivos sobre las relaciones entre estos ambientes en consideración a sus especificidades y diferencias. El eje central de esta lectura asume que las sociedades de esta región constituyen espacios relacionales con marcados procesos de segregación económica, de conflictos manifiestos y latentes en las esferas políticas y culturales, así como se trata de sociedades dependientes que se han incorporado a dos de los procesos antes mencionados de manera inducida. En la mundialización (globalización) y en el despliegue tecnológico, las sociedades de la región latino caribeñas se han visto involucrada por las fuerzas de los hechos provocados en las potencias económicas de América y Europa (Gallardo, 1995).

Los procesos de mundialización y despliegue tecnológico en la región han evidenciado el carácter diferenciado — no se ha dado de la misma manera en las sociedades del globo y ello depende directamente de su posición en la estructura de relaciones de fuerza que por siglos se han asentado-; y asimétrico, en tanto ha producido extraordinarias ganancias para un mundo rico que se desarrolla a alta velocidad $\mathrm{y}$ ha develado vulnerabilidades extremas en un mundo pobre masivo y que recibe mayormente los sobrantes de la actual forma de desarrollo (Gallardo, 1995).

Por su parte, los procesos de individualización propios de las tensiones que ha sufrido la lógica y racionalidad con que se desplegaba la modernidad en las sociedades de la región, ha tendido más bien a transformarse en procesos de individualismo de la mano de lógicas de seguridad ciudadana - versión democratizada y civil de la doctrina de seguridad nacional, en que se pasó del enemigo externo por razones ideológico y políticas del tiempo de dictaduras, al enemigo interno por amenaza contra la propiedad privada en tiempos de gobiernos civiles en la región- (Ramos y Guzmán, 2000). Así, estos procesos de ensimismamiento, lejos de producir potenciamientos y autonomías de las y los individuos, más bien están derivando en situaciones de egoísmo social, sostenidas en relaciones de abierta desconfianza al otro u otra, a quienes se percibe como amenaza (Figueroa, 2003). Estos procesos en su variante economicista han dado pie a la gestación de la ideología del emprendimiento, que amparada en la idea de surgir y crecer, promueve los esfuerzos individuales como estrategia para salir de las 
situaciones de vulnerabilidad; en esta ideología lo colectivo y las transformaciones estructurales no son condición de posibilidad para su logro sino que incluso pueden llegar a ser un obstáculo.

En referencia a los modos de hacer política, nuestra región viene mostrando desde principios de los noventa — cuando se consolidaba el proceso de fin a las dictaduras militares y de instalación de gobiernos civiles - procesos que tienden a la fragmentación social, a la autonomía de esferas vitales como el Estado y la política, y fuertemente en la región, procesos de corrupción del ámbito político, como una «tendencia a configurarse como un espacio autónomo de intercambio de privilegios derivados de posiciones de poder entre los actores políticos que dejan de ser interlocutores del conjunto de una sociedad 'bien ordenada' (sociedad civil) y pasan a ser interlocutores para sí mismos» (Gallardo, 1995:20).

Se plantea entonces una evidente contradicción en que «junto a los notables éxitos de la modernización existe un difuso malestar social» (Lechner, 2007). Según el Programa de Naciones Unidas para el Desarrollo, los indicadores macroeconómicos y macrosociales considerados como buenos, no otorgan necesariamente sentimientos de seguridad y protección en la población (PNUD, 1998). Esta condición societal se puede observar empíricamente en tres ámbitos:

a) El miedo a la exclusión: a pesar de las amplias ofertas existentes para acceder a bienes en diverso ámbitos, la población manifiesta incerteza e inseguridad para lograr aprovechar esas oportunidades, lo que provoca «fuertes sentimientos de inequidad y desprotección» (Lechner, 2007). Dicho temor se acentúa en el contexto ya señalado de desconfianza en las relaciones interpersonales.

b) El miedo al otro: en Chile mientras se mantienen las tasa de criminalidad, la percepción de temor en la población aumenta exponencialmente (Ramos y Guzmán, 2000), lo que expresa metafóricamente un conjunto de temores en que la presencia de otros/as concebidos/as como extraños/as es significada como de potenciales agresores. Los vínculos sociales debilitados y la ideología de no alternativas profundizan en esta situación (Gallardo, 1995).

c) El miedo al sinsentido: diversos problemas sociales que se verifican en la actualidad - aceleración de la cotidianidad, contaminación medioambiental, consumos de drogas de diverso tipo, violencias naturalizadas - inciden en una percepción de «la vida social como un proceso caótico» (Lechner, 2007). Los referentes institucionales habi- 
tuales (familia, escuela, trabajo, nación) son percibidos como desprovistos del influjo estructurador que tuvieron en el pasado, y aumenta la sensación de tensión para la elaboración de sentidos individuales en un proyecto de vida.

De esta forma, con Lechner concebimos que una de las características matrices de esta época es que la gente no se percibe parte de «una modernización que parece avanzar a sus espaldas ni es la beneficiaria de las nuevas oportunidades» (2007) que se anuncian, siendo vital este plano de la subjetividad para comprender los modos de estructurar lo comunitario y la comunidad. A este contexto algunos autores en un enfoque que no privilegia la clave modernidad-modernización, le denominan capitalismo salvaje (Dierckxsens, 2007; Borón, 2003); de esta forma dan cuenta de los altos costos que está implicando su despliegue actual en vastos sectores de la población que, desde las diversas esferas de su vida, padecen empobrecimiento, vulnerabilidad y exclusión. Los efectos de esta modernización están implicando dolores sociales y en el mismo movimiento tienden a sostenerse sobre la idea que ya adelantamos: lo colectivo y comunitario como una ilusión que puede obstaculizar más que aportar a integrarse a esta modernidad bullante.

En este escenario es posible interrogarse por la pertinencia política que tiene indagar por las posibilidades de construcción de comunidad. ¿De qué comunidad podríamos hablar en clave de acción política? ¿Cómo la acción juvenil puede aportar en dichos procesos comunitarios?

Abordando estas dos interrogantes hemos de reflexionar en torno a la noción de comunidad que estamos refiriendo. Ésta ha sido debatida en su acepción idílica que plantea una suerte de asimilación de comunidad con la existencia esencial de atributos como el bienestar, la acción compartida y la felicidad humana. Por otro lado, y tal como señala Caride, si bien se reconoce su polifonía y derivaciones semánticas, existe un conjunto de significados que apuntan a institucionalidades de diversa cobertura (local, regional, nacional e internacional); ámbitos de convivencia social; "prácticas, servicios e iniciativas de alcance colectivo»; hasta ciertas corrientes de pensamiento (2006). De ahí que podría constituir una cierta trampa este uso polifónico que no logra delimitar con precisión de qué se habla, produciendo homogenización en las realidades a las que se refiere, mitificando las tensiones y polémicas en dichas realidades, resolviendo a favor de los discursos hegemónicos de los grupos con capacidad de control, y que toda estra- 
tegia de comunidad implica que debe ser única y consensuada (Barbero y Cortés, 2005 en Caride, 2006).

En ese sentido, desprovista la noción de comunidad de estos significados, por lo demás apriorísticos, se requiere dotarla nuevamente de sentidos que partan por considerar el carácter de construcción social de la misma, por lo tanto el dinamismo y especificidad que dichos significados adquirirán: dinamismo referido a la permanente transformación de las condiciones en que se origina comunidad, en tanto los contextos se modifican y las/os actores ahí vinculados también cambian en una dialéctica infinita; y, especificidad, ya que los contextos poseen características culturales, sociales, políticas, ambientales propias y sus gentes que les habitan, también se van moldeando en relación con estos contextos.

A partir de este dinamismo y especificidad, concebimos comunidad como las diversas resultantes de procesos sociales de articulación de sentidos en la acción colectiva, que otorgan una cierta unidad en torno a elementos comunes a las y los sujetos que en dichos procesos se vinculan. Estos elementos comunes pueden ser parte de la raíz y puntos de partida de los procesos, así como de sus producciones o de sus propósitos y resultados, vale decir aparecen en todos los trayectos que la producción de comunidad implica.

Refiriéndonos a las experiencias de producción de comunidades desde los mundos juveniles en sectores empobrecidos, las iniciativas desplegadas y sistematizadas nos muestran tres de estos elementos: los territorios en que dichas comunidades se producen-concretizan, el ambiente que les da cuerpo, y las subjetividades que se producen con el sentido de pertenencia (Duarte, 2004, 2006 y 2010).

a) La acepción de territorio, en diálogo con Caride, va más allá de las delimitaciones técnicas y burocráticas, y nos invita a poner énfasis en los elementos que remiten a las «coordenadas espaciotemporales contextuales y medio ambientales (ya que), siguen desempeñando un papel clave en la explicación y comprensión de las realidades sociales, así como de los procesos de acción-intervención social que se pretenden implementar, respecto de los que el territorio - al que es necesarios descargar de sus connotaciones cartográficas y administrativas - siguen funcionando como un sustrato significativo de las interacciones sociales y del comportamiento sociocultural» (2006). Para el caso de los mundos juveniles, diversas investigaciones (Pérez y Mejía, 1997; Espinoza, 1999) muestran como la vinculación al terri- 
torio, entendido como el espacio donde se vive (barrio, villa, provincia) y/o estudia (liceo, universidad, etc.), donde se despliega una cierta acción colectiva (plaza pública, parque para práctica de deportes, centros de consumo, etc.) ha venido a constituirse en las últimas décadas en referente que otorga elementos para la articulación de sentidos identitarios. «Es así como las culturas juveniles reconfiguran la noción de territorio, vinculado a los límites geográfico-administrativos, resignificando éstos en territorios culturales, comprendiéndolos como la construcción subjetiva de una territorialidad que es signada por las marcas culturales que dejan las múltiples apropiaciones y trayectos que realizan los y las jóvenes a través de sus prácticas de recreación y creación cultural en espacios de encuentro cotidiano ubicados, tanto en la población (como la esquina, la calle, la plaza) en que viven, como en otros espacios de la ciudad que van más allá de su territorio local» (Duarte, 2004).

b) La noción que se aúna a territorio es la de ambiente y refiere a la densidad y características que asumen las relaciones sociales que las y los sujetos despliegan en los diversos territorios que habitan. Los modos de relacionarse en una colectividad y percibir - objetivardichas relaciones constituyen una dimensión fundante de lo comunitario, en tanto aportan elementos vitales para construir los marcos de interpretación de las experiencias ahí vividas (Delgado, 2009). En ese sentido, «comunidad es más inteligible cuando se objetiva o matiza con otras expresiones que la acompañan (escolar, religiosa, vecinal, científica, cultural, familiar, etc.), reflejo de la cohesión y socialización que generan distintas formas de estar en el mundo y de adoptar un marco cultural con el que definir ciertos ámbitos de la vida cotidiana de las personas» (Caride, 2006, cursiva en el original).

c) Esta triada conceptual se completa con la noción de sentidos de pertenencia, que refiere a las significaciones que las y los sujetos atribuyen a sus experiencias y a los imaginarios que en torno a ellas construyen para delimitar sus modos de anclaje en sus vidas. En los mundos juveniles «la pertenencia territorial constituye en este tiempo un elemento que fortalece el proceso de construcción de identidades en las y los jóvenes. Lo que en décadas pasadas lo conformaba la identidad de clase, que en el caso de las juventudes se planteaba por su procedencia familiar: ser hijo de obrero» 0 «ser hijo de clase media», hoy día tiene una expresión alojada en lo simbólico que se enraíza en el territorio desde el cual se proviene» (Duarte, 2004). En este sentido, y lo mostraremos más adelante, la capacidad de participación — como 
ser y hacerse parte de un proceso- que despliega cada sujeto/a en su experiencia es vital para potenciar este sentido de pertenencia a una cierta comunidad «uno se siente comunidad, si se implica. Uno se siente comunidad, si puede participar. Uno se siente comunidad, si está conectado. Implicación, participación y conexión son, sin duda, factores que ayudan a crear comunidad, a crear sentido de pertenencia» (Subirats, 2002; 36 en Caride, 2006).

Estas tres dimensiones del orden subjetivo retoman el planteo de Lechner (2007) respecto a que los procesos de modernización están desplegándose distanciados, y podemos agregar en contradicción, con los intereses y sueños de las y los sujetos sociales. Dicha constatación no niega la relevancia de las subjetividades sino que enfatiza su importancia a partir de la dialéctica relación existente entre sus producciones específicas y los procesos sociales en los cuales ellas se dan (Muñoz, 2009). En ese sentido, la interrogante por los tipos de sociabilidad, los modos de lo colectivo en los procesos de individualización y en definitiva las posibilidades de comunidad se vuelven pertinentes y urgentes, más aún si se considera el contexto antes analizado.

Las lógicas del capitalismo salvaje ya señalado, apuntan en la dirección de la no comunidad, constituyendo nuevas formas en una época de «sálvese quien pueda». Se niegan la producción de sentidos compartidos que motiven la activación en pos de acciones conjuntas, pues por una parte, se señala que ya no habría alternativa posible a las dificultades existentes - habríamos llegado a un estado superior de desarrollo al modo de «fin de la historia» (Fukuyama, 1992) - , y por otra, porque se incita a entregar las capacidades de cambio y activación a la clase política para que represente dichos deseos si es que existieran - lo que tiende a volverse nulo en el contexto de corrupción y de la desafección política- (Gallardo, 1995). También se promueve la imagen de una cierta desterritorialización de las relaciones sociales, ideologizando la construcción de una cierta sociabilidad que perdería humanidad ante la influencia de la virtualidad de las redes computacionales y de internet (Sandoval, 2003) y no se observa que ellas, lejos de negar las vinculaciones cara a cara, al menos en el caso de los mundos juveniles que acceden al uso de tecnologías de la comunicación, más bien las acercan y adelantan, lejos de negarlas (Pavez, 2008), así como están permitiendo vinculaciones más allá de las fronteras nacionales (Beck y Beck-Gernsheim, 2008). En esta polémica, una estrategia posible para abordar las intenciones de comunidad pro- 
viene de la acción comunitaria. Sobre ello reflexionaremos en lo que sigue de este apartado.

Interesa comenzar planteando que acción comunitaria es, «antes que nada, un tipo de acción social» (Llena y Úcar, 2007). Concebir la acción comunitaria como una acción social posibilita asumir su carácter fundante de lo social, su relación con los imaginarios en que ella se recrea y al mismo tiempo, acentuar que se trata de una producción social, estructurante del ser social, así como de la sociedad misma.

De igual forma, la acción comunitaria puede ser comprendida en el horizonte que provee el concepto de acción colectiva, que para Delgado implica «un fenómeno social que alude al proceso de coordinación de acciones entre individuos, organizaciones y movimientos sociales. Igualmente, se asume que uno de sus principales objetivos es influir de alguna manera en los entornos sociopolíticos y culturales en los que se desenvuelve» (Delgado, 2009). Intereses y deseos que en ciertos marcos de acción son definidos — de manera latente o manifiesta - por quienes se articulan en pos de propósitos de transformación de sus entornos y de sus propias vidas, en dialéctica relación con dichos entornos.

Con estos elementos en consideración, la acción comunitaria puede ser definida como un «macro concepto o un concepto inclusivo, dado que abarca todo un conjunto de acciones desarrolladas por una multitud de actores — que puede incorporar o no a profesionales - y que hacen referencia a espacios y escenarios compartidos. En dichas acciones se consensuan objetivos y se pactan significados de cara a alcanzar unas metas que se orientan hacia la transformación social. Estas acciones suponen el encuentro de lógicas y miradas e interpretaciones diversas que tratan de establecer un espacio común para el entendimiento; éste les permite compartir y participar en el desarrollo de unas acciones determinadas: las acciones comunitarias (Llena y Úcar, 2007).

De esta manera esta noción de acción comunitaria especifica y vincula las nociones previas de acción social y acción colectiva, al mismo tiempo que establece su potencialidad en tanto interrelación mancomunada, que apunta a la transformación social y la mejora en la vida de las personas, que implica reflexividad de estos actores para comprender sus contextos - territorios, ambientes-, desplegando procesos que den cuenta de sus subjetividades — sentidos de pertenencia, identidades —. ${ }^{1}$

1 Igualmente, acción comunitaria vincula y contiene un conjunto de conceptos específicos que remiten a desarrollo comunitario, trabajo social comunitario, intervención comunitaria, animación socio cultural, orga- 
Desde estos elementos se abren perspectivas para analizar la activación con los y las jóvenes, como posibilidad de construcción de comunidad en sectores empobrecidos en Chile. Previamente, hay una característica particular que se ha develado en estos territorios y que es preciso considerar en esta argumentación y que refiere a los (des)encuentros generacionales que se producen en dichos territorios. Estas situaciones aportan dificultades y oportunidades necesarias de tomar en cuenta en esta reflexión, sobre ello trabajaremos en el apartado siguiente.

\section{3. (DES)ENCUENTROS GENERACIONALES EN EL TERRITORIO}

Haciendo foco, de aquí en adelante en esta reflexión, en los mundos juveniles de sectores empobrecidos latino caribeños, encontramos que las dimensiones señaladas del actual contexto se viven con crudeza. Las vulnerabilidades analizadas y los procesos de empobrecimiento de distinto tipo están afectando de manera grave a las generaciones más jóvenes, siendo dicha condición generacional — así como la de género y etnia - atributos identitarios que remarcan dichas situaciones de exclusión (INJUV, 2010).

A estas situaciones hemos de agregar un componente que incide de manera relevante en las experiencias que se proponen el despliegue de procesos de acción comunitaria en los contextos descritos. Dicho componente refiere a las relaciones intergeneracionales que en ellos se verifican y que podemos identificar como tendientes en su mayoría a los desencuentros (Duarte, 2002). Diversas investigaciones y sistematizaciones de experiencias muestran algunas características de estas relaciones que podemos conceptualizar como:

a) Relaciones intergeneracionales de tipo adultocéntricas: refiere a la matriz socio cultural que configura tanto los modos de relación social, las estructuras organizacionales, como los imaginarios producidos en torno a lo adulto y lo juvenil —así como de otras generaciones- en nuestras sociedades (Duarte, 1996). En esas producciones lo adulto es significado como lo potente, valioso y modelo a seguir,

nización comunitaria, apoyo social, entre otros, que no constituyen el eje de esta reflexión, pero que dan cuenta de la densidad política que tiene el enfoque asumido de la acción comunitaria. Para profundizar en dichos conceptos ver Llena y Úcar, 2007. 
siendo las y los adultos concebidos como quienes poseen control respecto de las y los demás, inhibiéndoles sus posibilidades de despliegue y crecimiento al resto de grupos y generaciones (Duarte, 2001).

b) Indisposición y desconfianza ancestral de las y los jóvenes: lo anterior lleva cada vez más a que las y los sujetos jóvenes desplieguen sus relaciones con los mundos adultos posicionados desde la desconfianza y en ocasiones desde el temor (INJUV, 1996). La reproducción de relaciones de dominio desde los mundos adultos, inhiben los desarrollos juveniles en los términos que éstos últimos desean e imaginan (Bourdieu, 1990). Estas situaciones son de mayor complejidad y densidad que los procesos de diferenciación en el marco de las construcciones identitarias, en que también las y los jóvenes remarcan lo que diferencia y aleja por sobre lo que puede asemejarse y unir.

c) Estigmas desde los mundos adultos que niegan capacidades en los y las jóvenes: las y los adultos tienden a desarrollar imaginarios y relaciones que reproducen la condición adultocéntrica, que tiene una de sus fuentes de nutrición en los estigmas construidos en torno a los modos de ser y hacerse joven de cada época (Muñoz, 2004). Priman por sobre todo las nociones negativas que apelan a una cierta condición esencial de maldad de las y los jóvenes; y aquellas de tipo positiva, que muestran una esencia vinculada a la pureza, no sólo son menos en frecuencia (Duarte, 2002), sino que son aquellas que desde los mundos adultos se definen como las esperadas y adecuadas socialmente. De esta forma las y los jóvenes, sus acciones y discursos son construidos como problemas sociales que producen desconfianza, ya que se trataría de individuos sin capacidades de aporte en la sociedad (Duarte, 2003).

d) Mundos adultos con pocas o nulas habilidades y muchos temores: estas construcciones desde prejuicios deshumanizadores, inciden en mundos adultos con pocas habilidades para relacionarse con sus jóvenes y con muchos temores a lo que podrían implicar relaciones democráticas y equitativas. Las diferencias en lo cotidiano tienden a ser resueltas por la sola imposición de la condición de «mayor» de parte de uno/a de los involucrados/as - en el liceo y en la universidad, en la familia, en el trabajo, en la organización social, en la política pública-; y muchos adultos/as reconocen sentir temor/pavor por las nuevas tendencias o estilos juveniles, lo que utilizan como justificación para actuar de forma unilateral (INJUV, 1996). 
En el contexto descrito, de tendencias al individualismo y al ensimismamiento, las estructuras organizacionales barriales son asumidas mayoritariamente por adultos y adultos mayores, que reproducen los desencuentros señalados. Esto ha implicado que las relaciones intergeneracionales sean de baja calidad y que las posibilidades de trabajo conjunto o al menos colaborativo sean escasas (Muñoz, 2010). De uno u otro lado se tiende a evitar el vínculo.

Las organizaciones vecinales tradicionales (Juntas de Vecinos y Clubes deportivos, por ejemplo) son dirigidas por personas adultas y adultas mayores, con bajísima participación de jóvenes, salvo en algunos deportes masivos, en que niños, niñas y jóvenes son quienes componen los equipos de cada categoría, pero no ocupan puestos de liderazgo y dirección.

De esta forma, los modos de acceder a la participación en sus territorios por parte de las y los jóvenes, se estructuran desde la perspectiva de ganar espacios y de resistir a las prácticas adultocéntricas de las y los mayores (Duarte, 2004). Una de las concepciones a la base de sus experiencias es la sospecha y a veces desconfianza respecto de las intencionalidades y posibilidades de trabajo conjunto con adultos y adultas de organizaciones e instituciones. Su principal queja refiere a que se sienten utilizados y manipulados con fines que no responden a sus necesidades e intereses, sino que dan cuenta de propósitos que están predefinidos desde estos adultos.

Si consideramos el contexto antes analizado de fragmentación y vulnerabilidades, un ejemplo que podemos considerar es que para los mundos adultos, las y los jóvenes no sólo implican su liquidación simbólica sino también una abierta competencia en los espacios laborales. Porque las nuevas generaciones cuentan con mayor cantidad de años de estudio y con mayor sensibilidad a la inclusión de los soportes tecnológicos para el desarrollo laboral. Ambos capitales constituyen una premisa de que estarían mejor calificados para asumir los puestos vacantes del mercado laboral y empujar la salida de los adultos de segunda generación. La contracara de esta situación es que la posesión de «experiencia laboral», es medida en años de trabajo, y sigue siendo un factor de peso en el mercado laboral, cuestión que termina incidiendo en el momento de definir a quienes contratar. Un dato empírico que evidencia esta última situación, es que los niveles de desempleo en Chile muestran que, para la cohorte entre 18 y 29 años, la tasa es desde hace décadas el doble del promedio nacional y que en los sectores empobrecidos puede llegar al triple (INJUV, 2010). 
Otro ejemplo de estos desencuentro se observa en el plano de las imágenes que cada grupo generacional elabora respecto del otro. Desde los mundos adultos se tienden a relevar las imágenes elaboradas desde el prejuicio negativo sobre las características, intereses y acciones juveniles. De esta forma, un conjunto de estigmas ordenan las posibles relaciones entre adultos/as y jóvenes, materializando profundos procesos de deshumanización de dichas relaciones (Duarte, 2003). Criminalización, satanización, terrorificación, apatía e incluso anomia son las ideas fuerzas producidas respecto de las y los jóvenes, lo que evidencia (mal)trato, inhibiendo relaciones de encuentro y posible colaboración. La sospecha permanente y la desconfianza hasta la descalificación son parte de la cotidianidad de estos (des)encuentros. Hemos de señalar que los medios de comunicación constituyen un artefacto que alienta este tipo de construcción de imaginarios, con permanentes muestras de la peligrosidad juvenil (Duarte y Littin, 2002).

Desde los mundos juveniles arrecia la desconfianza. En algunos casos con argumentos provenientes de sus propias experiencias como víctimas de mal trato - familia, escuela, organización social de algún tipo-. Sin embargo, lo que se observa es que no existe reflexión crítica de dichas experiencias sino que se resuelve a través de la totalización de las mismas, homogenizando a las y los adultos como individuos que manipulan, reprimen y dificultan llevar adelante las propuestas juveniles (Duarte, 2004).

De esta forma podemos observar que estos desencuentros generacionales en el territorio dan cuenta de disputas y polémicas que tienen raíces diversas, pero que en concreto debilitan las posibilidades de acción comunitaria conjunta, así como refuerzan las tendencias a la fragmentación que se estimula desde el contexto global.

Estos desencuentros y «puentes rotos» (Duarte, 2002) existentes entre mundos juveniles y mundos adultos se verifican, entre otros ámbitos, en aquellos que refieren a los modos de acción con que se implementan experiencias comunitarias con jóvenes. Sobre esto reflexionamos en el próximo apartado.

\section{4. (DES)CRITERIOS EN LA ACCIÓN CON JÓVENES}

En este contexto se pueden observar experiencias de acción comunitaria en que participan jóvenes, para reflexionar sobre la incidencia de estos elementos contextuales en ellas. La idea a la base es que se producen tensiones en las estrategias metodológicas de estas experiencias 
a propósito del contexto de fragmentación, de la reproducción de la matriz adultocéntrica y de la poca claridad en la perspectiva de comunidad que se utiliza. La mirada de esta dimensión apunta a relevar uno de los componentes de la acción comunitaria que refiere los criterios que se utilizan en estas experiencias para definir sus estrategias metodológicas, a partir de la interrogante sobre los aportes a la construcción de comunidad, los modos de vinculación de las y los jóvenes y la contribución a la transformación social.

Esta observación la hacemos en perspectiva generacional, vale decir intentando poner de relieve los modos en que, en cada uno de los criterios que consideraremos, se despliegan las relaciones entre generaciones, en especial entre jóvenes y adultos/as. Estos criterios apuntan a algunos de los aspectos que han resultado hallazgos de investigaciones sobre experiencias de acción comunitaria en que participan jóvenes y no pretenden agotar el campo, sino señalar las que aparecen como más relevantes (en base a Duarte, 2004, 2006 y 2010).

a) ¿A qué apuntan nuestras acciones: a procesos o a actividades? Muchas veces las acciones desplegadas en las comunidades no apuntan necesariamente a procesos sino que tienden a agotarse en múltiples actividades de corto plazo y con pocas o nulas conexiones entre ellas. Es necesario plantearse la producción y despliegue de procesos de largo plazo que permitan tener mayor incidencia en las realidades que se pretenden transformar. Por ello es importante revisar cuál es la interrogante que se plantea al diseñar estas acciones: ¿qué queremos hacer? o ¿qué queremos lograr?, la primera de ella remite a actividades y la segunda al diseño de procesos.

Por otro lado, cuando se actúa sólo desde las actividades suele ocurrir que las evaluaciones quedan reducidas a diversos aspectos de orden procedimental y logístico, dejando de lado, cuestiones relevantes como por ejemplo si el contexto de acción se modificó en algún sentido a partir de dichas acciones, si se lograron cambios significativos en las acciones de determinados sujetos, etcétera.

La interrogante por los procesos apunta entonces a definir con claridad qué aspectos de las realidades personales, locales, nacionales, interesa transformar o contribuir a su transformación.

b) ¿Cómo construimos poder desde nuestras acciones? Nuestras acciones son profundamente políticas. En esa línea es vital interrogarse por las transformaciones que se van logrando. Un indicador de esos cambios es que las poblaciones jóvenes y sus comunidades vayan 
asumiendo el control de sus vidas - autonomía, capacidad de opinión y deliberación, responsabilidad - y de las decisiones en los ámbitos que les importan — salud, trabajo, educación, cultura, recreación, medio ambiente, sexualidades, etc.-.

Abordar la vida de las poblaciones jóvenes y de sus comunidades remite a la constitución de sujetos que muestran capacidad para vincular sus logros personales con los logros colectivos de sus agrupaciones, familias y comunidades. En ese sentido se pretende que las y los sujetos jóvenes descubran el carácter político que tiene la acción comunitaria. Desde ahí entonces han de plantearse estrategias que asuman que no se trata de acciones sólo en lo individual, sino que debe considerarse la condición político-cultural que la misma tiene y los tipos de transformaciones a que se apunta.

Por ello deben asumirse los conflictos que se generan por estas acciones comunitarias. Es decir, lo que se haga o se deje de hacer con poblaciones jóvenes se vuelve profundamente conflictivo, porque la vida lo es. Además porque los enfoques desde los cuales se aborda, van en sentido contrario a lo planteado como tradicional y también porque se implementan acciones que otros no quieren hacer. Para esto, se ha de aprehender a asumir el conflicto - en su carácter políticocomo posibilidad de crecimiento-profundización y no como trauma que inmoviliza desde el miedo.

c) ¿Nos interesa incidir en las políticas locales, regionales y nacionales? No siempre se plantea como propósito de las acciones comunitarias la incidencia en las políticas locales y nacionales, lo que va mermando sus posibilidades de impacto y de sostenibilidad en el tiempo.

Se ha de abrir la mirada a constatar qué actores están involucrados en el campo de acción de la experiencia. Ellos pueden estar fuera de dicho campo, lo que implica que una línea de acción esté relacionada con conseguir por ejemplo, que asuman su rol de garantes de derechos y transformen actitudes anteriores que producían vulnerabilidad. Esto puede exigir que se incluyan acciones de sensibilización y compromiso de autoridades y actores con capacidad resolutiva para la implementación de políticas públicas. Esto puede ayudar a que los cambios obtenidos sean sostenibles en el tiempo, pues están respaldados por este tipo de instrumentos. Lo central es que dichas políticas puedan ser creadas de manera participativa, con amplio aporte de las propias poblaciones jóvenes y demás actores involucrados, a lo que llamamos co-construcción de políticas (Duarte, 2004; Iglesis, 2001). 
d) ¿Generamos sinergia en nuestra acción cotidiana? Llama la atención en la diversas experiencias observadas, la baja consideración del conjunto de las comunidades - territoriales, ambientales, etc.como posibles aliados para actuar de manera conjunta y colaborativa. Más bien, la acción se va reduciendo sólo a ciertos grupos o tipos específicos de jóvenes dentro de las poblaciones juveniles.

Por ello es vital, la visibilización de los diversos tipos de actores - agrupaciones de distinto tipo e instituciones - que existen en el territorio en que se actúa, por ejemplo a través de catastros en que se enfaticen los diversos recursos y energías con que cuenta cada actor y en qué ámbitos puede aportar. Esto permitirá establecer con quienes y de qué manera se pueden generar vínculos para actuar de manera conjunta, produciendo «enredamientos», acciones en red.

Al mismo tiempo, es necesario definir en qué momentos y qué tipo de vínculos han de establecerse, de manera que sean los ritmos y condiciones del contexto los que vayan dando luces sobre las acciones mancomunadas a desplegar.

Un aspecto relevante en este criterio apunta a la necesaria reflexión crítica en torno a la tendencia a la juvenilización que se observan en estas experiencias (Margulis, 1996). Refiere a la concentración exclusiva y que termina siendo excluyente de la experiencia sólo en jóvenes, evitando o no considerando la articulación con otros grupos generacionales. La propuesta apunta a la concepción de comunidad como un espacio intergeneracional, en que las dinámicas cotidianas están plenas de esa característica lo que exige su consideración como tal en la acción comunitaria. Es posible que en determinados contextos sea necesario mantener y promover agrupaciones juveniles, es decir integradas sólo por jóvenes, lo que se puede potenciar con experiencias de vinculación y colaboración con agrupaciones, organizaciones e instituciones formadas por otros grupos generacionales.

e) ¿Cuáles son los estilos pedagógicos en las experiencias? Una de las tensiones principales que se observan en diversas experiencias es que se reproducen lógicas escolarizadas en ellas. Algunas son: la frontalidad en el vínculo, la verticalidad del mismo, la transmisión unilateral de conocimientos y la no producción colectiva de los mismos, la no consideración de las experiencias de los y las jóvenes en el proceso, la no incorporación de la corporalidad como elemento fundamental en el proceso, la memorización y acumulación de información por sobre la experimentación y producción autónoma, entre otros. De esta forma, aquellas características centrales del proceso pedagógi- 
co escolar han de ser interrogadas para definir su pertinencia en el proceso que se pretende implementar. Uno de los aspectos específicos de esta modalidad escolar es lo que Freire denominó «bancaria» (2005), y que en la acción comunitaria con jóvenes aparece como la transmisión de conocimientos que invisibiliza y niega los aportes que las y los jóvenes pueden realizar.

Una alta incidencia en el cambio de los estilos pedagógicos en experiencias comunitarias en que participan jóvenes es el cambio de enfoque en lo que respecta a las concepciones con las cuales se les observa y comprende. Se requiere que quienes se vincularán con las y los jóvenes, se preparen en una epistemología de lo juvenil que discuta las nociones adultocéntricas, desnaturalice las explicaciones construidas sobre los modos de acción e imaginarios juveniles y que historice sus prácticas y propuestas, así como que sea capaz de distinguir los diversos modos de hacerse joven en nuestra sociedad. Esto en diálogos permanentes con las y los propios jóvenes que permitan reconstruir los modos autoritarios de ejercicio pedagógico, hacia estilos democráticos y liberadores.

f) ¿Qué relevancia tiene la consideración de lo territorial en las acciones comunitarias con jóvenes? A partir de lo señalado en el primer apartado de este texto, podemos enfatizar la necesidad de que el territorio - simbólico y/o material - tenga una inclusión estratégica en la acción comunitaria. Se trata del escenario en el cual se despliegan las acciones de las y los jóvenes y de sus comunidades; se trata de un referente en la producción de identidades a partir del sentido de pertenencia que contiene en esta época; y constituye el espacioambiente a que se refieren los cambios que se pretenden lograr: es lo que se quiere cambiar.

Los desafíos pedagógicos y metodológicos que ello implica apuntan a su inclusión como contenido de los procesos formativos y políticos que se desplegarán. Lo territorial puede ser un importante elemento de la conversación social que se implemente en el marco de los procesos de acción comunitaria y su vínculo con la comunidad que se pretende lograr puede favorecer y potenciar dicha conversación.

g) ¿De qué manera participan las y los jóvenes en las experiencias comunitarias? Una de las dimensiones de mayor debate en la acción comunitaria en que se vinculan jóvenes se relaciona con el carácter que asume la participación juvenil. Por ello, a lo largo de este texto he usado intencionadamente la noción de «vinculación de jóvenes», pues no da lo mismo señalar que se trata de experiencias «para 
jóvenes», «por la juventud», «desde las y los jóvenes», «con las y los jóvenes», «entre jóvenes», ya que aun vinculándose jóvenes en ellas puede tratarse de iniciativas «sin jóvenes». Las experiencias observadas muestran que las tendencias ideales según jóvenes y los equipos que se vinculan con ellos y ellas refiere que se construyan sentidos colaborativos e incluyentes «implementando estrategias con, desde y entre las poblaciones jóvenes» (Duarte 2006, cap. III:6).

En esa dirección Diego Palma sugiere avanzar en procesos comunitarios que se sostengan sobre lógicas de participación sustantiva, que se caracteriza por la virtuosa articulación entre las capacidades de participar y las oportunidades que en el contexto se producen para ello (1999). Complementario a ello, quienes conforman los equipos de educadores/as y profesionales, han de desplegar destrezas para observar y relevar las capacidades y potencialidades que poseen las y los jóvenes en tiempo presente y sus posibilidades de aportar en la construcción de sus vidas y la de su entorno cercano; esto requiere que, sin caer en una comprensión mesiánica de las y los jóvenes, se visibilicen sus aportes.

La acción comunitaria, comprendida como experiencia pedagógica (Úcar y Llana, 2006) puede potenciarse si se asume a estos jóvenes como protagonistas de su proceso, ello va en la dirección contraria a la escolarización —que les concibe sólo como receptores pasivos- y fortalece lo antes señalado en torno a una pedagogía que se co-despliega sostenida en la confianza en las y los jóvenes participantes de ella.

Esta participación protagónica ha de sostenerse sobre la información compartida, el debate profundo, las decisiones democráticas, la acción colectiva, el compromiso y el control de lo que se define hacer o dejar de hacer.

Estos criterios sugeridos para la acción comunitaria con jóvenes pueden aparecer incompletos, sin embargo insisto en su carácter dinámico y que la observación en ella también lo es, por lo que no existe pretensión de clausura. Desde esta mirada es que se sistematizaron estos siete criterios, que se ajustan a la orientación del texto en producción. Se trata de aquellos que muestran un vínculo más claro con la reflexión sobre la acción comunitaria con jóvenes y las articulaciones generacionales. Sobre este último aspecto reflexionamos en el apartado siguiente. 


\section{ACCIÓN COMUNITARIA Y CONSTRUCCIÓN DE COMUNIDAD. ALTERNATIVAS DE NUESTROS TIEMPO}

Si comunidad, decíamos antes, alude a la producción social de lo común a partir de acciones mancomunadas para la transformación societal, lo comunitario deviene en las características que le otorgan identidad a esos procesos. ¿Cuáles serían entonces las características de acciones comunitarias desplegadas desde mundos juveniles? ¿Cuáles serían sus aportes en procesos de construcción de comunidad en contextos de capitalismo salvaje?

Las sistematizaciones e investigaciones que surgen desde experiencias comunitarias con jóvenes muestran al menos tres características identitarias en estos procesos: solidaridad, autonomía y dignidad. Ha de considerarse que cada una de ellas no remite a un estado definitivo sino a la resultante de un proceso con tensiones y oportunidades.

a) Solidaridades de jóvenes. Si bien esta es una de las características más cercana a uno de los discursos estigmatizadores sobre jóvenes de las producciones adultocéntricas — «joven voluntario» como contrapartida al «joven violento»-, en este caso pretendemos relevar la propia identificación que los discursos de jóvenes producen para señalar una de sus principales motivaciones para agruparse y desplegar acciones sociales: «ayudar a los demás», «transformar la sociedad», «cambiar el estado de las cosas» (Duarte, 2002). Lo común, lo compartido, aquello que produce colectividad es la acción que beneficia a otros y aquella que se propone transformar las condiciones que producen muerte en vida.

b) Autonomías y capacidad de agencia. Resulta vital para las y los jóvenes activarse socialmente desde sus propias motivaciones e intereses, enfatizando que desean hacerlo «sin que haya otros que nos digan qué hacer» (Duarte, 2002). Esta noción de autonomía en la acción tiene una cara luminosa y es que releva las potencialidades y capacidades de hacer que las y los jóvenes muestran desde hace décadas en sus proyectos comunitarios - a pesar de las dificultades para las y los actores adultos de reconocerlo y respetarlo-, y al mismo tiempo, una cara oscura, que refiere al uso de esta capacidad en el extremo de la no vinculación con otros actores adultos/as, niños y niñas, etc., tendiendo a la ya mencionada juvenilización de la acción comunitaria.

c) Dignidad e identidades. Los sentidos de pertenencia para las y los jóvenes resultan vitales en su construcción identitaria: «yo soy 
punk», «soy de los de abajo», ${ }^{2}$ «amo mi skate», «soy pentecostal», muestran la relevancia de la vinculación hacia adentro de su grupalidad a partir de atributos identitarios que caracterizan a las diversas culturas juveniles. ${ }^{3}$ En ese sentido, la activación en sus comunidades les aportan parte de dichos atributos y resultan un piso fundante de su constitución identitaria. Ello es transformado en muchas oportunidades en condición de resistencia a los diversos modos de agresión simbólicas y/o materiales - que sufren de parte de los mundos adultos, por ello se transforma en una plataforma de lucha que apela a su condición de dignidad desde su producción de identidad.

Desde estas características, básicamente enunciadas, se abren perspectivas para analizar la activación con los y las jóvenes, como posibilidad de construcción de comunidad en sectores empobrecidos en Chile.

Para avanzar en esta lógica, algunas consideraciones se vuelven fundamentales: por una parte, la necesidad de que al hablar de jóvenes se expliciten los contextos en que esos jóvenes se despliegan, valorando y enfatizando las diversidades de modos de ser joven y de constituirse de las juventudes, de manera de no homogenizar discursivamente ni construir imágenes que no permiten establecer distinciones entre experiencias plurales y dinámicas.

Un segundo aspecto refiere a la necesaria valoración de las y los jóvenes en sí mismos, a partir de sus producciones propias y no siempre en comparaciones con lo pasado o con lo esperado. Vale decir, tensionar la capacidad analítica para que las y los propios jóvenes produzcan argumentaciones que fundamenten sus apuestas y que desde los mundos adultos se produzcan versiones sobre lo juvenil - diverso y pluralescuchando y significando en concordancia con lo que estos sujetos y sujetas plantean. Esto no constituye una apelación a la no crítica ni una búsqueda de asepsia en el análisis social, sino más bien refuerza la búsqueda de diálogos con las experiencias juveniles, para constituir puntos de encuentro de trayectos y proyectos comunes desde enfoques generacionales.

2 Barra del equipo de fútbol Universidad de Chile.

3 No uso la noción de culturas juveniles que enfatiza en la espectacularidad de las mismas (Feixa, 1998), sino más bien aquella que refiere a sus producciones y posicionamientos políticos en los territorios-ambientes en que se despliegan (Reguillo, 2000). 
En esa perspectiva se hace necesario disponer de otros lentes para mirar y comprender estos procesos de constitución de las y los jóvenes en nuestra historia y los modos de abordar las disputas que esos procesos plantean. Mientras mantengamos las lógicas de la carencia, el peligro y la amenaza social no lograremos avanzar en nuevas conceptualizaciones, reproduciremos los imaginarios y las prácticas asimétricas propias del adultocentrismo. De igual forma, mientras promovamos imágenes fundadas en racionalidades esencialistas que mesianizan a las y los jóvenes como portadores inherentes del cambio social, y les veamos como disponibles para la acción política porque son jóvenes y porque están viviendo una supuesta etapa de idealismos y rebeldías, seguimos reproduciendo nociones naturalizadoras del ser joven y de las disputas a que nos hemos referido.

Necesitamos cambiarnos los lentes. Mirar con otros ojos y abrirnos para relevar los posibles aportes que las y los jóvenes pueden hacer a la transformación de nuestras realidades. Para ello es vital aprehender a comprender los mundos juveniles desde sus potencialidades y capacidades, como ejes de nuevas lecturas. Es decir, partir desde la pregunta por las contribuciones que las y los jóvenes, en diversos espacios sociales, pueden hacer a las dinámicas colectivas, institucionales, etc.

Lo anterior implica poner en debate los modos de ejercer poder que los mundos adultos efectúan sobre los mundos juveniles, estructurando relaciones de dominación que inhiben el despliegue autónomo y digno de estos sujetos jóvenes. Al mismo tiempo, resulta propio de ese movimiento crítico, la elaboración de alternativas para la generación de estilos relacionales democráticos y de respeto generacional, buscando apoyar el reencuentro entre generaciones y al mismo tiempo el empoderamiento de los sujetos hasta ahora considerados «menores» en nuestra sociedad; niños, niñas y jóvenes. En ese sentido apostamos por la posibilidad de construir poderes colaborativos desde los espacios de vínculos cotidianos e íntimos que permitan acumular capacidad de control en pos de irradiar dichos logros hacia espacios locales y nacionales, en donde estos sujetos hasta ahora subordinados y ninguneados puedan constituirse como actores sociales, es decir ciudadanos en tiempo presente.

Estas relaciones equitativas/igualitarias/solidarias entre generaciones, sustentadas en el respeto y la colaboración, exigen aprendizajes que permitan la cooperancia intergeneracional (Duarte, 2007). Las estrategias hasta ahora usadas muestran que los diálogos intergeneracionales en territorios y comunidades específicas son una posibilidad para avan- 
zar en la reconstrucción de los «puentes rotos» (Duarte, 2006). En estos procesos «la vuelta a lo comunitario» puede ser potenciada sobre una «vuelta a la experiencia» como punto para gatillar la conversación social entre los diversos grupos generacionales. La transmisión de conocimientos en el estilo escolar de las sociedades industriales y la posesión-transmisión de información de las sociedades tecnologizadas, presentan modos relacionales entre generaciones que no siempre ayudan en estas perspectivas de colaboración. Las experiencias observadas muestras que las pistas culturales que los pueblos originarios entregan en sus vivencias, en que las relaciones entre grupos generacionales se daban principalmente a través de la transmisión de experiencias (Feixa, 1998), puede ser una clave a indagar para mirar las posibilidades de actualización-recreación en tiempo presente.

Este enfoque abre posibilidades también para las y los sujetos adultos, en tanto les posibilita rehacer las nociones tradicionales adultocéntricas que han significado, en el contexto de sociedades capitalistas, el ser adulto como lo autoritario, rígido, no afectivo, aburrido, establecido y con sensación de haber llegado a un punto terminal, es decir negando toda dinámica y recreación de las identidades de estos sujetos. Es por ello que esta apuesta por equidad, igualdad y/o solidaridad intergeneracional, también es una oportunidad para la constitución de sujetos/as adultos/as de nuevo tipo, con capacidad de soñar y de proponer alternativas, constituyendo una adultez alternativa a los modelos asimétricos y conservadores propios del adultocentrismo.

De esta forma, hemos planteado algunas pistas como posibilidades-oportunidades que se abren si se incorporan horizontes de equidad, igualdad y/o solidaridad generacional en la acción comunitaria con jóvenes. Esta acción comunitaria, en tanto acción humana que constituye sociedad, con sus fortalezas y debilidades, puede participar con alta incidencia en intentar enmendar el rumbo del malestar social, la fragmentación y el individualismo diagnosticado. La perspectiva de comunidad, en tanto construcción colectiva puede ofrecer alternativas de humanización, bien común y solidaridad. Las jóvenes y los jóvenes de sectores empobrecidos tienen un aporte vital que hacer en dichos procesos.

SANTIAGo (CHILE), OCTUBRE 2013

RECIBIDO: OCTUBRE 2013 ACEPTADO: DICIEMBRE 2013 


\section{REFERENCIAS BIBLIOGRÁFICAS}

BARBERO J. M. y F. CORTÉS (1995): Trabajo comunitario, organización y desarrollo social. Madrid: Alianza Editorial.

BAUMEN ZYGMUNT (2002): Modernidad líquida. México: FCE.

BECK, RULRICH (1999): ¿Qué es la globalización? Barcelona: Paidós.

BECK, ULRICH y ELIZABETH BECK-GERNSHEIM (2008): Generación global. Barcelona: Paidós.

BORÓN, Alitio (2003): Estado, capitalismo y democracia en América Lati$n a$. Buenos Aires: CLACSO.

BouRdieu, PIERRE (1990): «La juventud no es más que una palabra». En Sociología y cultura. México: Grijalbo.

CARIDE, José (2006): «La educación social en la acción comunitaria». En ÚCAR XAVIER y LLENA ASUN (coordinadores). Miradas y diálogos en torno a la acción comunitaria. Barcelona: Graó.

DÁVILA, ÓSCAR y CARMEN GLORIA HONORES (2003): «Capital social juvenil y evaluación programática hacia jóvenes». Última Década $\mathrm{N}^{\circ} 18$. Valparaíso: Ediciones CIDPA.

DELGADO, RicARDO (2009): Acción colectiva y sujetos sociales. Bogotá: Editorial Pontificia Universidad Javeriana.

DEL PICÓ, JoRGE (1994): «Perspectiva histórica de las políticas de juventud». Primer informe nacional de juventud. Santiago: INJUV.

DIERCKXSENS, WIM (2007): «América Latina y el Caribe y el camino al socialismo del siglo XXI». Revista Pasos $\mathrm{N}^{\circ} 137$. San José: DEI.

DuARTE, KlaUdio (2010): «Desafíos que las condiciones juveniles de América Latina y el Caribe le plantean a los procesos investigativos en juventudes». En Juventud: investigación-acción. Bogotá: Agencia española de Cooperación Internacional para el Desarrollo.

— (2006) Género, generaciones y derechos: nuevos enfoques de trabajo con jóvenes. Una caja de herramientas. La Paz: UNFPA y Family Care International.

_ (2005) «Trayectorias en la construcción de una sociología de lo juvenil en Chile». Persona y Sociedad, Vol. 19, N². Santiago: Universidad Alberto Hurtado.

(2004) Potencialidades juveniles en la co-construcción de políticas locales de juventudes. Santiago: ACHNU.

(2003) «Jóvenes entre la maldad y la pureza. A propósito de los treinta años del golpe militar contra el pueblo chileno». Revista ERIAL $\mathrm{N}^{\circ} 10$. Lo Espejo: Programa Caleta Sur.

(2002) «Mundos jóvenes, mundos adultos: lo generacional y la reconstrucción de los puentes rotos en el liceo. Una mirada desde la convivencia escolar». Última Década $\mathrm{N}^{\circ} 16$. Viña del Mar: Ediciones CIDPA. 
(2001) «iJuventud o juventudes? Versiones, trampas, pistas y ejes para acercarnos progresivamente a los mundos juveniles». En KLAUDIO DUARTE y DANAHÉ ZAMBRANO (editores): Acerca de jóvenes, contraculturas y sociedad adultocéntrica. San José: DEI.

- (1996) Juventud popular. El rollo entre ser lo que queremos o ser lo que nos imponen. Santiago: LOM ( $2^{\mathrm{a}}$ edición).

— y CATALINA LiTTIN (2002): Niños, niñas y jóvenes: construyendo imágenes en la prensa escrita. Santiago: ACHNU.

ESPINOZA, ATILIO (1999): «Mi barrio es zona crema: territorialidad y conflicto en un grupo barrial de la Trinchera Norte». En ALDO PANFICHI y MARCEL VALCÁRCEL (editores): Juventudes: sociedad y cultura. Lima: Red para el Desarrollo de las Ciencias Sociales en el Perú.

FeIXA, ChARLeS (1998): De jóvenes, bandas y tribus. Antropología de la juventud. Barcelona: Ariel.

FiguerOA, RoDRIGO (2003): Desempleo y precariedad en la sociedad de mercado. Santiago: RIL Ediciones y Universidad de Chile.

FreIRE, PAUlo (2005): Pedagogía del oprimido. México: Siglo XXI.

FUKUYAMA, FRANCIS (1992): El fin de la historia y el último hombre. México: Planeta.

Gallardo, Helio (1995): «América Latina en la década de los noventa». En Revista Pasos $\mathrm{N}^{\circ} 59$. San José: DEI.

IgLESIS, ANDREA (2001): «Políticas de juventud: entre la fragilidad y el desconcierto. Algunas pistas para construir rutas desde lo local». Última Década $\mathrm{N}^{\mathrm{o}} 14$. Valparaíso: Ediciones CIDPA.

InJUV (2010): Sexta encuesta nacional de juventud. Principales resultados. Santiago: INJUV.

INJUV (1996). Visión del mundo adulto con respecto a los jóvenes en la cultura urbana chilena. Santiago: INJUV.

LECHNER, NORBERT (2007): «Desafíos de un desarrollo humano: individualización y capital social». En KLIKSBERG y TOMASSINI (compiladores): Capital social y cultura: claves estratégicas para el desarrollo. Buenos Aires: BID/FCE.

LLENA, ASUN y XAVIER ÚCAR (2006): «Acción comunitaria: miradas y diálogos interdisciplinares e interprofesionales». En Xavier Úcar y ASUN LLENA (coordinadores): Miradas y diálogos en torno a la acción comunitaria. Barcelona: Graó.

MARGULIS, MARIO (editor) (1996): La juventud es más que una palabra. Ensayos sobre cultura y juventud. Buenos Aires: Biblos.

MuÑZ, ANTONIO (2010): «El voluntariado visto desde las y los jóvenes voluntarios claves para su comprensión». Revista Observatorio de Juventud $\mathrm{N}^{\circ} 26$. Santiago: INJUV.

MUÑOZ, VíCTOR (2004): «Condiciones 'post' y asociatividad juvenil: preguntas por lo político en México y Chile». Última Década №25. Valparaíso: Ediciones CIDPA. 
— (2004) «Imágenes y estudios cuantitativos en la construcción social de 'la juventud' chilena. Un acercamiento histórico (2003-1967)». Última Década N²0. Valparaíso: Ediciones CIDPA.

PALMA, DIEGO (1999): «La participación y la construcción de ciudadanía». Documento de Trabajo N ${ }^{\circ} 27$. Santiago: Universidad de Arte y Ciencias Sociales.

PAVEZ, MARÍA ISABEL (2008): «Nativos e inmigrantes digitales: caracterización exploratoria de estudiantes universitarios». Tesis de grado de Magíster en Antropología y Desarrollo. Santiago: Universidad de Chile.

PÉREZ, DIEGO y MARCO MEJÍA (1997): De calles, parches, galladas y escuelas; transformaciones en los procesos de socialización de los jóvenes de hoy. Bogotá: CINEP.

PNUD (1998): Desarrollo humano en Chile, 1998: las paradojas de la modernización. Santiago: PNUD.

RAMOS, MARCELA y JUAN GUZMÁN (2000): La guerra y la paz ciudadana. Santiago: LOM.

REDONDO, JESÚS (2005): «El experimento chileno en educación: ¿conduce a mayor equidad y calidad en la educación?». Última Década №22. Valparaíso: Ediciones CIDPA.

REguillo, Rossana (2000): Emergencia de culturas juveniles. Estrategias del desencanto. Buenos Aires: Norma.

SALAZAR, GABRIEL y JULIO PINTO (2002): Historia contemporánea de Chile. Niñez y juventud. Tomo V. Santiago: LOM.

SANDOVAL, MARIO (2003): Jóvenes del siglo XXI. Sujetos y actores en una sociedad en cambio. Santiago: Universidad Cardenal Raúl Silva Henríquez.

SUBIRATS, J. (2002): «Identidad y comunidad: los retos para la política y la educación». En AJUnTAMENT DE BARCElonA: Por una ciudad comprometida con la educación. Vol. 1. Barcelona: Institut d'Educació de 1'Ajuntament de Barcelona.

TIJOUX, MARÍA EMILIA (2002): «Cárceles para la tolerancia cero: clausura de pobres, y seguridad de ciudadanos». Última Década №16. Valparaíso: Ediciones CIDPA. 